\title{
Health Canada contemplates providing food industry with "discretionary" authority to fortify junk foods
}

Published online at www.cmaj.ca on May 12, 2009

$\mathrm{F}$ ortified junk food, from potato chips to energy bars to fruitflavoured drinks, may soon be appearing on grocery store shelves across Canada.

But it's still junk food, warn dietitians and other health professionals, who fear that a Health Canada proposal to allow vitamin and mineral (iron, calcium, etc.) additives in high-calorie food with little nutritional value will increase its consumption by a populace already prone to obesity and diabetes.

The department's thinking behind the proposed policy change - which would leave it to the discretion or choice of food manufacturers to fortify their products - is that if people are going to eat junk food they may as well get the nutrients.

The amendments to the Food and Drugs Regulations were scheduled to be published in the Canada Gazette on Mar. 31, but Health Minister Leona Aglukark yanked them for further review. "She balked at the prospect of being labelled the Fortified Junk Food Queen," says a Health Canada official.

Another official adds that there continues to be a "serious split" within the department about the merits of fortifying junk food. Some believe that it would spur growth of the processed food industry and provide a health benefit for consumers, while others warn it would promote greater consumption of junk food.

It also remains to be seen how much pressure the processed food industry can put on government departments and cabinet to proceed with the regulatory change, the official adds.

Certainly, there appears to be little appetite within the nutrition community for discretionary fortification.

Dietitians of Canada supports the fortification of foods when there is a "clear public health need," says Lynda Corby, a registered dietitian and public affairs director of the association.

But it does not support leaving the decision to fortify foods to industry.

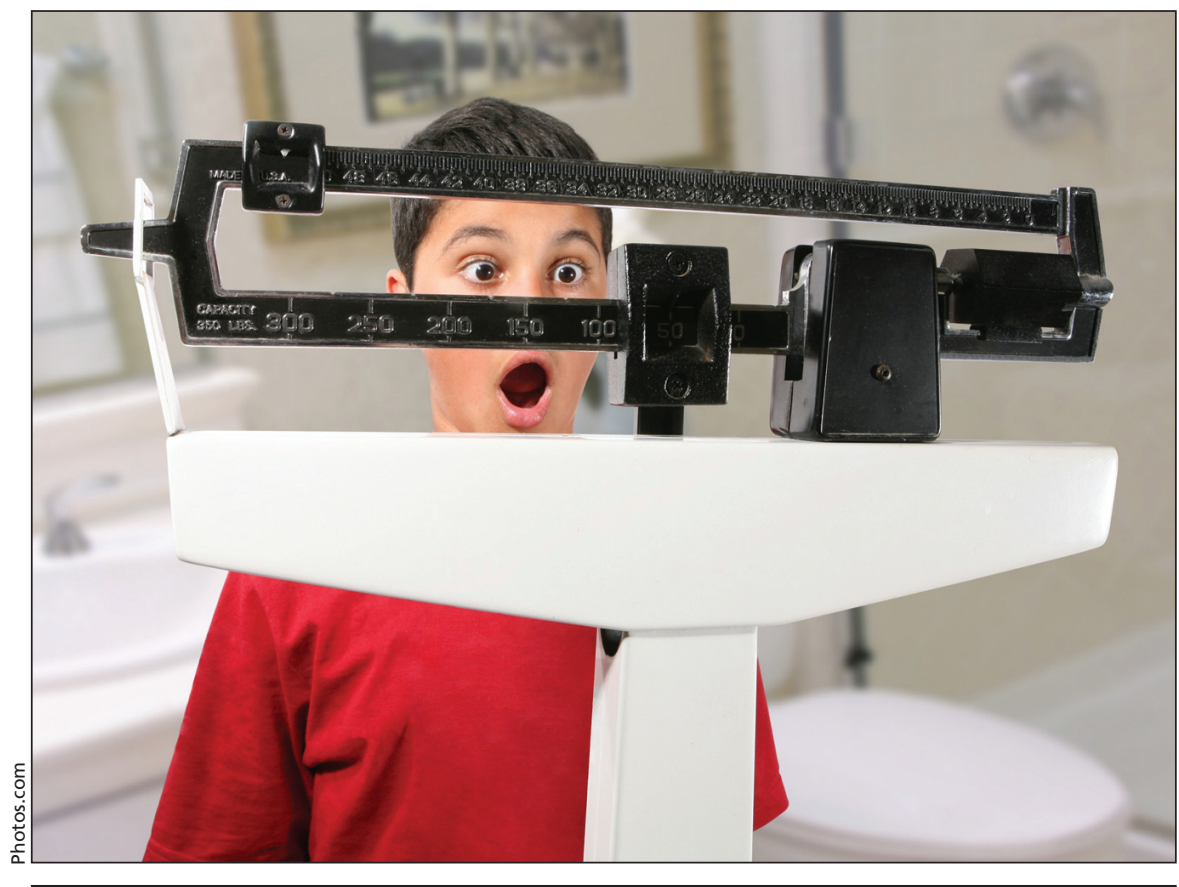

Nutritionists fear that fortifying junk food will promote consumption of such foods.

"There is a potential - if high-fat, high-energy foods are fortified with vitamins (or) minerals at the discretion of the industry - for Canadians to choose these foods in place of healthier whole food options, which may add to the obesity problem in Canada. We feel that children and youth are particularly vulnerable to this practice."

Health Canada's rationale for discretionary fortification doesn't hold water, argues Dr. Yoni Freedhoff, medical director and coowner of the Bariatric Medical Institute, a weightmanagement centre in Ottawa, Ontario.

"I'm not aware of a rash of microor macronutrient deficiencies in the population that need rapid correction," Freedhoff says. "I can appreciate that if there were some sort of massive public health crisis of vitamin deficiencies, giving the food industry the ability to fortify foods would be a useful plan of action but given that we're all fine, this is really misguided and panders to the food industry."

"The food industry's job is to sell food and not to protect health. To allow them to discretionarily fortify food is worrisome," Freedhoff adds, saying that it would invariably lead to fortification of foods whose consumption nutritionists would not want to encourage. "Yet, with the fortification, the food industry will have ample ammunition with which to advertise how helpful their food has now become. And we know that front-of-package health claims do, in fact, influence consumer behaviour. ... Therefore, it might steer people to choose less healthy options. It might influence people to consume more of a less-healthy option. And the worst-case scenario is that it influences people who are already eating healthy foods to choose, highly-processed, lesshealthy options."

But Health Canada spokesperson Christelle Legault states in an email that "some stakeholders have repeatedly expressed concerns that the existing regulations are overly restrictive. These stakeholders have indicated their concern that case-by-case amendment of the regulations is a lengthy process that inhibits the development of new products and limits access by Canadian consumers to foods with added vita- 
mins and mineral nutrients, including products that are readily available in other countries."

Background Health Canada documents indicate the department doesn't consider the move a health risk, although some vitamins and minerals can produce adverse effects if consumed in excessive quantities.

"Discretionary fortification, the optional addition of any nutrient from a defined list of vitamins and minerals over defined ranges at the discretion of manufacturers, is expanded to allow for a wider range of fortified products which would provide for more food sources of nutrients without increased risk to health," the department states (www .hc-sc.gc.ca/fn-an/nutrition/vitamin/faqs -eng.php).

Focus group testing also indicates that fortification would not lead to increased consumption of junk foods, Health Canada added. "Those who already consume ice cream or carbonated beverages indicated that they might choose the fortified counterpart if there was no difference in any other aspect of the food including taste and price, but they did not indicate they would consume more."

For the food industry, the changes would harmonize Canadian policy with the more relaxed regulations in the United States, which allow such products as Goldfish crackers fortified with calcium.

Proponents argue that the move would facilitate trade. A major industry group that has advocated the policy change, Food and Consumer Products of Canada, refused comment on the proposals before they are announced publicly by Health Canada.

Spokesperson Catherine Baker says that "when the regulations come out we'd be more than happy to talk about them." - Eric Beauchesne, Ottawa, Ont. and Wayne Kondro, CMAJ

DOI:10.1503/cmaj.090897

\section{More news at www.cmaj.ca}

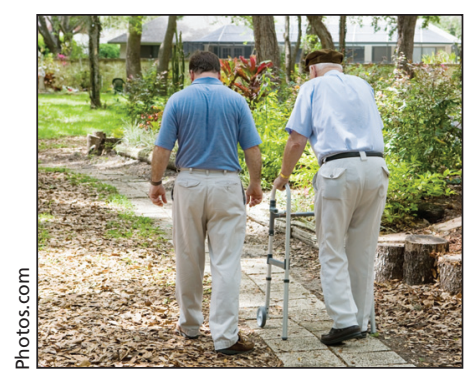

Home care: Growing demand for home care spurs calls for national standards and a pan-Canadian program. - Krista Seggewiss, Ottawa, Ont.

Preparedness: Canadian response to the $\mathrm{A}(\mathrm{H} 1 \mathrm{~N} 1)$ swine influenza outbreak was significantly swifter than during the 2003 SARS outbreak. - Ann Silversides, CMAJ

Pandemic scale: The World Health Organization revises its 6-point scale for determining when a pandemic should be declared. - Roger Collier, CMAJ

Swine: The first case of human-to-human transmission of swine flu within Canada is confirmed by Nova Scotia health authorities. - Wayne Kondro, CMAJ

Dispatch: An Israeli physician recalls missiles lobbed across the border. - A. Mark Clarfield, MD, Beersheva, Israel.

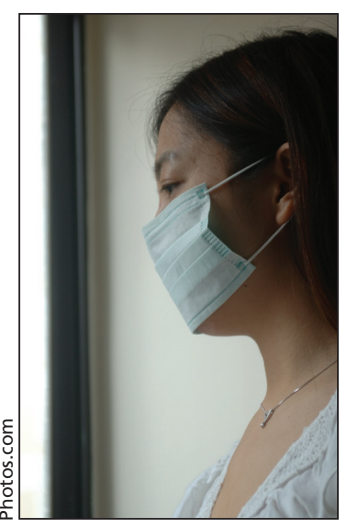

DOI:10.1503/cmaj.090880

\section{Briefly}

Creative marketing: Testimony before the Federal Court of Australia indicated that drug giant Merck paid a division of medical publishing giant Elsevier to produce several volumes of a fake journal, The Australasian Journal of Bone and Joint Medicine, to flog the merits of its products, particularly the antiarthritis drug rofecoxib (Vioxx). The case involves an Australian man who claims the drug caused him to have a heart attack in 2003. He alleges that Merck downplayed the cardiovascular risk of the drug prior to withdrawing it from the market in 2004. In a statement to the online news magazine The Scientist, an Elsevier spokesperson said that the company "does not today consider a compilation of reprinted articles a 'Journal'. Elsevier acknowledges the concern that the journals in question didn't have the appropriate disclosures. It is worth noting that the project in question was produced 6 years ago and disclosure protocols have evolved since 2003."

Pharmakiosks: Ontario Minister of Health and Long-Term Care David Caplan says the province will allow drug dispensing machines to be set up in remote areas. Patients would insert their prescriptions and converse with a pharmacist at a call centre by videoteleconference. The pharmacist would verify the prescription and instruct the machine to dispense the drug. Caplan said potential benefits include patient convenience, a new made-in-Ontario industry and lower drug distribution costs.

Aging: An integrated health and social services plan and bolstered pensions are desperately needed to assist elderly Canadians, says a Senate Special Committee on Aging. Chaired by Senator Sharon Carstairs, the committee makes 32 recommendations to improve the lot of seniors, including dedicated federal financial transfers to provinces with a higher proportion of seniors (www.parl.gc.ca). - Wayne Kondro, CMAJ 